\title{
Determinantes sociales en salud que influyen en la prevalencia de la infección por VIH en mujeres trabajadoras sexuales de la zona céntrica de la ciudad de Armenia, Quindío, Colombia
}

Social determinants in health that influence the prevalence of HIV infection in women sex workers in the downtown area of the city of Armenia, Quindío, Colombia

\author{
Edward Vela Osorio ${ }^{a}$ \\ asociación Ágora Colombia. Programa de Salud Sexual y \\ Reproductiva. Armenia, Quíndio, Colombia. \\ E-mail: edric_12ळhotmail.com

\section{Dannys Alberth Aguirre Ocampo ${ }^{b}$} \\ ${ }^{\text {b} A s o c i a c i o ́ n ~ A ́ g o r a ~ C o l o m b i a . ~ A r m e n i a, ~ Q u i ́ n d i o, ~ C o l o m b i a . ~}$ \\ E-mail: dann-alberthळhotmail.com \\ Jair Eduardo Restrepo Pineda ${ }^{c}$ \\ 'Corporación Universitaria Minuto de Dios. Facultad de Ciencias \\ Humanas y Sociales. Bello, Antioquia, Colombia. \\ E-mail: jair.restrepo®uniminuto.edu
}

\section{Correspondencia}

Jair Eduardo Restrepo Pineda

Corporación Universitaria Minuto de Dios, Facultad de Ciencias Humanas y Sociales. Bloque 3, piso I, carrera 45 número 22D-25. Bello, Antioquia, Colombia.

\section{Resumen}

El artículo tiene como objetivo analizar los Determinantes Sociales en Salud (DSS) que influyen en la prevalencia de la infección por VIH/Sida en mujeres trabajadoras sexuales de la zona céntrica de la ciudad de Armenia, Quindío, Colombia. Para tal fin, se desarrolló una investigación cualitativa de carácter analítico y descriptivo, en la cual se emplearon, como instrumentos para la recolección de la información, entrevistas semi-estructuradas y grupos focales. Estas herramientas permitieron obtener información relativa a aspectos sociodemográficos, redes de apoyo, conocimientos sobre VIH/Sida y Derechos Humanos, Sexuales y Reproductivos (DDHH-SSR) de las mujeres trabajadoras sexuales que se ubican en la zona céntrica del municipio de Armenia. Para el análisis de la información, se realizó una matriz correlacional de los factores sociales en salud, así como un análisis de contenidos de los discursos de las mujeres que fueron entrevistadas y de aquellas que hicieron parte de los grupos focales. Los resultados de la investigación permitieron corroborar la complejidad del modelo estructural en salud, y la necesidad de realizar acciones intersectoriales que posibiliten transformar la realidad de las mujeres dedicadas al trabajo sexual de manera tal que se minimice su vulnerabilidad frente al Virus de Inmunodeficiencia Humana.

Palabras clave: Serodiagnóstico del Sida; Trabajo Sexual; Mujeres; Condiciones Sociales; Prevalencia. 


\section{Introducción}

This article aims to analyze the Social Determinants in Health (DSS) that influence the prevalence of HIV infection in sex-working women in the downtown area of the city of Armenia, Quindío, Colombia. For that reason, a qualitative investigation of analytical and descriptive character is found, in which semi-structured interviews and focus groups are used as instruments for the collection of information. These tools made it possible to obtain information on socio-demographic aspects, support networks, knowledge about HIV/AIDS and Human, Sexual and Reproductive Rights (HR-SSR) of the sex-workers located in the central area of Armenia. For the analysis of the information, a correlational matrix of the social factors in health was made, as well as an analysis of the contents of the women who were interviewed and of the focus groups. The results of the research allowed us to corroborate the complexity of the structural model in health and the need to carry out intersectoral actions that made possible the transformation of the reality of women engaged in sex work in a way that minimizes their vulnerability to the Human Immunodeficiency Virus.

Keywords: AIDS Serodiagnosis; Sex Work; Women; Social Conditions; Prevalence.
El VIH/Sida es un problema de salud pública que afecta a millones de personas en el mundo. Según datos de Onusida, para el 2016 cerca de 36,7 millones de personas vivían con la infección, de las cuales 17,8 millones eran mujeres mayores de 15 años. Los datos muestran que en América Latina viven 1,8 millones de personas con VIH/Sida, y que la cobertura del tratamiento en 2016 llegó solo al 58\% de todas las personas que vivían con la infección en los países de la región (Onusida, 2018).

Para el caso de Colombia, según datos que se manejan a través del Boletín Epidemiológico del Instituto Nacional de Salud, en su número 52, para el año 2013 se notificaron 8796 nuevos casos de infección por VIH/Sida, mientras que para el 2014 la cifra aumentó a 10093 casos, y para el 2015, a la semana 52, se habían reportado 11606 casos, lo que muestra un aumento de los casos reportados entre los años 2013 y 2015; es decir, la transmisión de la infección en el país sigue en aumento.

Por otra parte, el Ministerio de Salud y Protección Social de Colombia (2014) indica que en el país la infección por VIH suma cada vez más casos; de acuerdo con los datos de notificación de VIH/Sida al Sistema Nacional de Vigilancia en Salud Pública (Sivigila), desde 1985 hasta el 31 de diciembre del año 2013 se habían notificado 92379 casos. Este dato comprueba que el VIH/Sida ha ido incrementando su número de casos en Colombia, generando una gran preocupación a las entidades de salud, tanto en los ámbitos locales como nacionales.

En este sentido, el artículo pretende brindar desde una perspectiva interdisciplinar una comprensión de los Determinantes Sociales en Salud (DSS) que pueden influir en la prevalencia de la infección por el Virus de Inmunodeficiencia Humana (VIH) en mujeres cisgénero y transgénero de la zona céntrica de la ciudad de Armenia, Quindío. Los DSS son definidos como "aquellas condiciones sociales en las cuales se desarrolla la vida de las personas y que afectan el estado de salud de la población en distinto grado, de acuerdo a diversos factores, generando inequidades" (Vega; Jadue; Marín, 2005, p. 79). En este mismo sentido, la Organización Mundial de la Salud (2009, p. 3) 
sostiene que "los determinantes sociales de la salud explican la mayor parte de las inequidades sanitarias, esto es, de las diferencias injustas y evitables observadas en y entre los países respecto a la situación sanitaria”. Por esta razón, es indispensable considerar el impacto que en la actualidad tiene el deterioro de la calidad de vida de la población, derivado de diversos y complejos factores sociales, políticos, económicos y ambientales, ya que la "distribución desigual de experiencias perjudiciales para la salud no es, en ningún caso, un fenómeno «natural» ... Los determinantes estructurales y las condiciones de vida en su conjunto constituyen los determinantes sociales de la salud" (OMS, 2008, p. 14).

Algunos estudios sobre DSS se han centrado en realizar revisiones documentales que permitan identificar este tipo de factores en poblaciones específicas, como el caso de las mujeres indígenas (Juan-Martínez; Castillo-Arcos, 2016), o en áreas geográficas puntuales, como en los municipios del Valle del Cauca en Colombia (Tovar-Cuevas; Arrivillaga-Quintero, 2011).

En el año 2012, la Organización No Gubernamental Prosalus - Salud y Desarrollo - realiza una publicación titulada: VIH/Sida y determinantes sociales de la salud, en la cual sostiene que "el VIH/Sida es un asunto de derechos humanos: la falta de acceso a métodos de prevención, información y materiales apropiados, tratamiento y cuidados que conducen a la vulnerabilidad al VIH, está vinculada a violaciones de los derechos humanos, tales como la pobreza, la desigualdad, el racismo y el sexismo" (Prosalus, 2012, p. 1). Además, sostiene que la relación entre la pobreza y el VIH es compleja de tal manera que quienes viven en contextos de pobreza presentan mayores probabilidades de enfermar y fallecer más rápidamente debido a condiciones de nutrición y acceso a cuidados de salud apropiados. Así mismo, se considera que la pobreza y el VIH están fuertemente relacionados con el género, de esta manera los "determinantes sociales y económicos generan dependencias y vulnerabilidades en las mujeres, debido a la escasa educación, salarios bajos y desiguales, oportunidades limitadas de trabajo, estatus de inmigración y patrones migratorios, barreras lingüísticas, seguro de salud inadecuado, y poco acceso al cuidado de salud" (Prosalus, 2012, p. 1).

En esta misma línea, algunos investigadores como Liscano Pizón y Estrada Montoya (2015, p. 117) han llegado a la conclusión de que "los determinantes estructurales (género y condición socioeconómica) reportan una alta probabilidad de ejercer mayor condicionamiento sobre el comportamiento del VIH, por tanto se requiere de ingentes esfuerzos en este campo para combatir la pandemia”. Además, las situaciones de exclusión social, discriminación y marginalidad que viven las mujeres en situación de pobreza, y en especial las mujeres transgénero, conducen a aumentar su vulnerabilidad frente al VIH/Sida, siendo necesario en estos casos estudiar y comprender sus factores sociales.

Teniendo en cuenta estas consideraciones, el artículo se centrará en el análisis de los determinantes sociales en salud que influyen en la prevalencia de la infección por VIH/Sida en mujeres trabajadoras sexuales en condiciones de pobreza y exclusión social de la ciudad de Armenia, Quindío, con el fin de mostrar otras perspectivas, ya que "persiste un predominio de las investigaciones en VIH/Sida que se concentran en temas clínicos, dejando de lado el problema de la determinación social de la infección" (Tovar-Cuevas; ArrivillagaQuintero, 2011, p. 114). Tal como lo sostiene Santos Padrón (2011, p. 136):

se necesitan procesos de investigación sobre los determinantes sociales, más abarcadores y sustentados en buenas evidencias. También, reconocer la utilidad de estas investigaciones para tomar decisiones, orientadas a solucionar los problemas de salud con enfoques aproximativos a sus determinantes y no exclusivamente desde la atención médica.

Atendiendo a estas recomendaciones, se diseñó una investigación cualitativa interdisciplinar que permitió abordar los diferentes DSS que afectaban a las mujeres dedicadas al trabajo sexual en la zona céntrica del municipio de Armenia, Quindío, de manera tal que se logró 
un proceso de comprensión integral que superó la visión biologicista y permitió trascender al entendimiento de los sujetos sociales en un contexto específico, el cual se haya expuesto a constantes cambios culturales, políticos, económicos y ambientales, entendiendo estos como el origen de muchas de las enfermedades que hoy son consideradas problemas de salud pública.

\section{Metodología}

El artículo tiene como finalidad analizar los determinantes sociales en salud que influyen en la prevalencia de la infección por VIH/Sida en mujeres trabajadoras sexuales transgénero y cisgénero de la zona céntrica de la ciudad de Armenia, departamento del Quindío en Colombia. Para cumplir este objetivo, se realizó una identificación de los determinantes sociales en salud de esta población, posteriormente se procedió a clasificar las tipologías de los DSS, y finalmente se realizó un análisis donde se relacionaron la función de los determinantes sociales en salud con la prevalencia del VIH en las mujeres trabajadoras sexuales.

Los sujetos participantes en la investigación corresponden a mujeres en ejercicio de trabajo sexual de la zona centro de la ciudad de Armenia, las cuales habían sido identificadas a través de lideresas pares que participaron en el Proyecto VIH del Fondo Mundial que se desarrolló en los departamentos de Risaralda y Quindío durante los años 2014 y 2015.

Se establecieron los siguientes criterios de inclusión para las participantes en la investigación:

- Mujeres mayores de 14 años.

- Se incluyen tanto mujeres cisgénero como mujeres transgénero (transexuales, travestis, transformistas).

- Las mujeres deberían dedicarse al trabajo sexual.

- El ejercicio del trabajo sexual debía realizarse en la ubicación geográfica determinada para el presente estudio, es decir, la zona céntrica del municipio de Armenia.

- Las mujeres deberían ser referidas por otras personas ya entrevistadas durante el desarrollo de la investigación.
El muestro se desarrolló a través del sistema de bola de nieve o cadena, permitiendo captar los casos que generen interés mediante las referencias poblacionales de los líderes pares del sector (Martínez-Salgado, 2012); por tanto, la muestra obtenida es no probabilística e intencionada, la cual responde a los criterios de inclusión antes señalados.

En cuanto a las herramientas utilizadas durante la realización de la investigación, se encuentra la entrevista semi-estructurada, seleccionada debido a que su "flexibilidad permite obtener información más profunda, detallada, que incluso el entrevistado y el entrevistador no tenían identificada, ya que se adapta al contexto y a las características del entrevistado" (Díaz-Bravo et al., 2013, p. 166). La entrevista se encontraba distribuida en 4 apartados diferentes, siguiendo algunos criterios utilizados por Restrepo Pineda (2016) en su investigación referida a las percepciones y a los imaginarios sobre el VIH/Sida. El primer apartado correspondía a los datos sociodemográficos de las entrevistadas, tales como edad, sexo, identidad de género, nivel educativo, entre otros. En segundo lugar, se indagaba sobre las redes de apoyo, que permitían evaluar el apoyo social y familiar en los aspectos cognitivo, material y emocional con los cuales contaban estas mujeres; en tercer lugar se preguntó sobre los conocimientos en materia de VIH/Sida, y finalmente, se consultó a los sujetos participantes sobre derechos humanos y derechos sexuales y reproductivos (DDHH-SSR).

Además, se desarrolló una serie de grupos focales con las mujeres trabajadoras sexuales, que permitieron conocer sus conductas y actitudes sociales, lo que ayudó a revelar información sobre los DSS, así como a obtener mayor cantidad y variedad de respuestas que lograron enriquecer la información respecto a este tema. Los grupos focales permitieron complementar la información suministrada a través de las entrevistas semi-estructuradas, toda vez que lograron dar cuenta de comportamientos sociales y de las prácticas cotidianas que desarrollaban estas mujeres.

El análisis de la información se realizó a través del diseño de una matriz correlacional, que "es un proceso de pensamiento que implica el examen sistemático de algo para determinar sus partes, las relaciones entre las partes, y sus relaciones con el 
todo" (Spradley, 1980 apud Quecedo; Castaño, 2002, p. 25). La matriz permitió determinar las relaciones directas e indirectas entre los diferentes factores sociales y la incidencia del VIH/Sida en la población de mujeres trabajadoras sexuales objeto de la investigación. Esta matriz se complementó con un análisis de contenidos de los discursos de las mujeres entrevistadas, además de la conformación de perfiles fundamentados en los factores inherentes a los DSS.

Finalmente, es necesario resaltar que el proceso investigativo fue llevado a cabo mediante el desarrollo de actividades gestionadas por la Asociación Ágora Colombia, como servicio comunitario del Proyecto VIH Fondo Mundial, contando con el acompañamiento interdisciplinario de los profesionales que forman parte de esta entidad, así como con el apoyo de lideresas mujeres trabajadoras sexuales del municipio de Armenia.

\section{Consideraciones éticas}

Para este estudio, la garantía de confidencialidad y anonimato de la información se convirtió en la premisa fundamental para su desarrollo, por esta razón, se hizo un uso adecuado, seguro y confidencial de la información obtenida, y se protegió el nombre de las participantes mediante su anonimización; además se utilizó un sistema de doble codificación, a partir de pseudónimos, lo que garantizó que el personal técnico diferente al grupo de investigación no conociera la identidad de las personas participantes. Por otra parte, y teniendo en cuenta la participación de menores de 14 años, se realizó la firma de un asentimiento informado por parte de sus representantes legales o adultos responsables. Asi mismo, todas las mujeres debieron firmar un consentimiento informado, donde se les brindó información certera sobre los objetivos, el alcance de la investigación y los posibles beneficios y riesgos de participar en la misma. Dentro del consentimiento informado, se incluyeron apartados referidos a la aceptación de participación libre y gratuita en la investigación, la libre posibilidad de retiro, y los datos de contacto de los encargados de la investigación. Finalmente, se les dio a las participantes la garantía de recibir respuesta a cualquier pregunta y aclaración a cualquier duda acerca de los procedimientos, riesgos, beneficios y otros asuntos relacionados con la investigación y el tratamiento del sujeto.

\section{Resultados}

\section{Caracterización sociodemográfica de las trabajadoras sexuales}

Con el fin de acceder a los sujetos participantes en la investigación, se definió que se tendrían en cuenta a todas aquellas mujeres dedicadas al trabajo sexual que lo ejercieran en la zona céntrica de la ciudad de Armenia, sin tener en consideración el tiempo de permanencia en dicho lugar o su lugar de procedencia. Esto debido a que esta población es considera flotante, es decir, que varían constantemente de lugar, de residencia, o se desplazan de otros municipios o departamentos a este sector para ofrecer servicios sexuales. Por lo tanto, fue más eficaz y eficiente para el desarrollo de la investigación localizarlas en la zona donde ejercen la prostitución que en sus lugares de residencia.

En total, hicieron parte del estudio 122 mujeres, entre mujeres cisgénero y mujeres transgénero, que ejercen el trabajo sexual en la zona definida para el estudio. Dicha zona estaba comprendida entre las calles 12 y la 25 , y entre las carreras 18 y 16 del municipio de Armenia, departamento del Quindío. Los sitios de referencia de esta zona son la Cejita y La Plaza de Banderas, así como el Centro Administrativo Municipal y la Iglesia San Francisco.

Esta zona ha sido históricamente utilizada por la población que ejerce y ha ejercido el trabajo sexual en la ciudad, el cual se ha consolidado alrededor de diversos locales comerciales y sitios de ocio como bares, residencias, hoteles, cafés, billares, entre otros, donde se expenden y consumen bebidas alcohólicas y no alcohólicas. Vinculado a estos lugares, se evidencia una oferta permanente de sustancias psicoactivas ilegales, tales como la marihuana, el bazuco y la cocaína; en este contexto se ha promovido y consolidado el comercio sexual en la ciudad. Además, este sector presenta problemas ambientales, tales como contaminación visual, auditiva y atmosférica, así como problemas sociales relacionados con el microtráfico de sustancias psicoactivas, extorsión, robos y demás situaciones de inseguridad. 


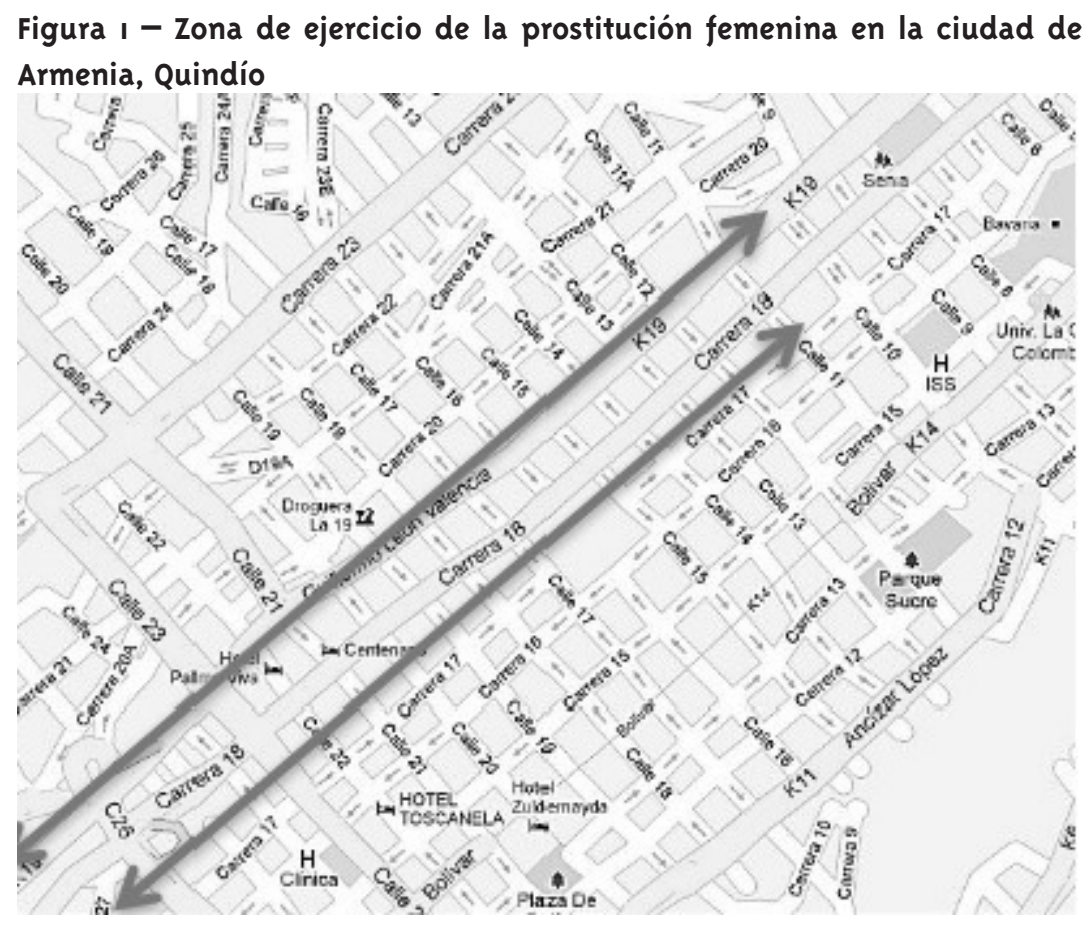

Fuente: Google Maps, 2017

El total de mujeres contactadas en la zona fue de 122, las cuales se dedicaban al trabajo sexual; de estas, 17 son mujeres transgénero, es decir, el $14 \%$ de las entrevistadas, frente al $86 \%$ que corresponden a mujeres cisgénero. En cuanto a sus edades, se realizó una distribución en cuatrienios, que permitió agrupar a las entrevistadas con relación a las etapas del desarrollo humano. Así, el $11 \%$ de la población entrevistada era adolescente, con edades que van de los 14 a los 19 años; por su parte, el $72 \%$ eran adultas jóvenes, las cuales se encontraban en un rango de edad de 20 a 40 años, el 13\% eran adultas en etapa de madurez o adultez, es decir, entre los 41 y 59 años de edad, y finalmente se encontraban las adultas mayores, con un $4 \%$, que tienen en común la dedicación al trabajo sexual desde etapas anteriores de sus vidas (Bordignon, 2005).

Del total de las mujeres entrevistadas, el 6\% corresponden a menores de edad en ejercicio del trabajo sexual, mayoritariamente adolescentes transgénero que manifiestan no ser de la región, además de carecer de una red de apoyo social y residir en la ciudad alejadas de su grupo familiar.
En términos de escolaridad, la educación formal en Colombia se estructura en cuatro niveles: preescolar, básica, media y superior. En relación con los niveles de escolaridad de la población objeto, se advierte que el $11 \%$ de las mujeres entrevistadas no tienen ningún tipo de educación formal, el $20 \%$ tienen la primaria completa y $18 \%$ incompleta, el $8 \%$ tienen secundaria completa y el $41 \%$ secundaria incompleta, y un restante $2 \%$ cursó por lo menos un semestre de educación superior. Se puede decir entonces que el $89 \%$ de las entrevistadas estuvo vinculada al sistema de educación y, de este, el 61\% terminó la educación básica y el 10\% la educación media, evidenciando una deserción considerable del sistema de educación, máxime cuando el 83\% de estas mujeres son adolescentes y adultas jóvenes.

Por tanto, se puede aseverar que no existe una limitación generalizada para el acceso de estas mujeres al sistema educativo, pero sí existe un grave problema en cuanto a su permanencia en este, situación que podría considerarse uno de los DSS. Los testimonios de dos de las mujeres entrevistadas ponen en evidencia esta situación: 
Yo empecé a estudiar pero me tocó salirme, porque cuando estaba en el colegio se burlaban mucho de mí, porque era muy femenina, entonces yo me aburrí y me salí. (Mujer transgénero, 32 años)

A mí siempre me gustó estudiar, pero no pude seguir porque tenía que ayudar en mi casa y me tocó ponerme a trabajar, al principio en un bar, pero ya luego de prostituta. (Mujer cisgénero, 27 años)

Estos dos testimonios evidencian que existen factores sociales que determinan las condiciones de vida de estas mujeres, que a su vez vienen a condicionar su salud, situaciones que, como los sostiene la OMS (2008), no son fenómenos "naturales", sino que corresponden a situaciones de inequidad, desigualdad e injusticia social.

En cuanto a vinculación al Sistema General de Seguridad Social en Salud (SGSSS), el 65\% cuenta junto a su grupo familiar con un cupo en las Administradoras de Régimen Subsidiado (ARS) del Ministerio de Salud y Protección Social (Minsalud), y el $17 \%$ está dentro de los ciudadanos encuestadas por el Sistema de Identificación de Potenciales Beneficiarios de Programas Sociales (Sisben). Sin embargo, este último grupo aún no ha obtenido el cupo para pertenecer al régimen subsidiado y, por tanto, tienen prelación para ser atendidos en la red pública de servicios en salud, por esta razón son considerados dentro del sistema como población vinculada. De otro lado, el $2 \%$ de las entrevistadas pertenece al régimen contributivo, y el $16 \%$ no tiene ningún tipo de afiliación. Esta última situación obedece principalmente a su característica de población flotante, ocasionando que algunas de las personas desconozcan si se encuentran vinculadas de alguna manera al sistema de salud en sus ciudades de origen.

En cuanto al aspecto económico, el 91\% de la población entrevistada vive en condiciones de pobreza extrema, entendidas como "las personas que residen en hogares cuyos ingresos no alcanzan para adquirir una canasta básica de alimentos, incluso si los destinaran en su totalidad a dicho fin. A su vez, se entiende como "pobreza total" la situación en que los ingresos son inferiores al valor de una canasta básica de bienes y servicios, tanto alimentarios como no alimentarios" (ONU, 2010). El restante $9 \%$ de las mujeres viven en condiciones de pobreza, logrando satisfacer "algunas" necesidades básicas como la alimentación y la vivienda.

Por otra parte, al indagarse sobre los antecedentes de estas mujeres en cuestiones de salud, se encontró que un $37 \%$ de las entrevistadas tenía o había sufrido algún tipo de enfermedad física, entre estas afectaciones cardiacas, infecciones de transmisión sexual, específicamente VIH/Sida, infecciones respiratorias, ente otras. Un 18\% había sufrido algún tipo de enfermedad psicológica o mental, y un $45 \%$ consumía algún tipo de Sustancia Psicoactiva (SPA). Este último factor contribuye tanto a los problemas de salud física como mental que afectan a las mujeres trabajadoras sexuales, aumentando las condiciones de vulnerabilidad a las que están expuestas.

En cuanto a la infección por VIH/Sida, la Asociación Ágora Colombia, a través del proyecto VIH del Fondo Mundial, realizó el diagnostico de 7 de las 122 participantes en este estudio, entre los años 2013 y 2015, lo cual representa el 5,74\% de la población entrevistada en esta investigación, evidenciando la prevalencia de la infección dentro de las mujeres trabajadoras sexuales.

De otro lado, se realizó un analisis de las redes de apoyo de las entrevistadas, obteniendo como resultado que el $85 \%$ de ellas manifiestan no tener ningún tipo de apoyo, ni emocional ni material, es decir, carecen de un respaldo por parte de sus familias o amigos, y no cuentan con una red institucional pública o privada que les permita hacer frente a situaciones negativas, conflictos o necesidades personales. Un 10\% de las mujeres manifiestan que obtienen el apoyo material y emocional por parte de sus familiares y amigos. Finalmente, solo un $5 \%$ de las mujeres entrevistadas recurre a organizaciones no gubernamentales o gubernamentales cuando requieren algún tipo de ayuda para hacer frente a determinadas situaciones.

Estos datos nos llevan a concluir que los programas y proyectos de intervención social, adelantados por las administraciones locales y regionales, no impactan de manera eficaz y eficiente a las poblaciones más vulnerables, puesto que estas mujeres desconocen este tipo de servicios sociales, lo que aumenta su vulnerabilidad social. Sumado a esto, sus situaciones de vida personal que han 
influido de manera negativa en las dinámicas y relaciones familiares las han conducido a carecer casi por completo del apoyo familiar.

En cuanto a los conocimientos que tienen las mujeres entrevistadas frente al VIH/Sida, a las Infecciones de Transmisión Sexual (ITS) y a los Derechos Humanos, Sexuales y Reproductivos (DH-DSR), se pudo constatar que el $58 \%$ tenían conocimientos bajos respecto a estos temas, generalmente conocían de la existencia del VIH/Sida y otras ITS, pero desconocían totalmente los temas referidos a los DH-DSR. El $15 \%$ de las entrevistadas se ubicaban en un rango de conocimientos medios, ya que conocían aspectos más puntuales sobre el VIH/Sida y las ITS, tales como las formas de transmisión, tratamiento, estrategias de prevención, así como conocimientos sobre DH-DSR, por su parte un $2 \%$ estaban en un rango alto de conocimientos, especialmente aquellas personas que habían hecho parte de procesos de formación y liderazgo desarrollados por diferentes organizaciones, tanto públicas como privadas. Finalmente, un $25 \%$ de las entrevistadas no tenían ningún tipo de conocimientos sobre estos temas, o los conocimientos que poseían eran imprecisos y estaban fundamentados en mitos, creencias y supuestos.

En términos generales, el 83\% de la población entrevistada está en situación de alta vulnerabilidad, puesto que sus conocimientos no les permiten hacer frente a los riesgos asociados al VIH/Sida, a las ITS y a la explotación sexual. Dicho esto, no se trata de poner de manifiesto que el trabajo sexual en sí constituya un riesgo, se trata de evidenciar que existen ciertos factores asociados a esta actividad que ponen a las mujeres en mayor vulnerabilidad que otros colectivos sociales. Por lo tanto, es necesario no solo que las mujeres tengan información precisa y confiable, sino que esta esté orientada de tal forma que la incorporen a nivel actitudinal y práctico, para que así se vuelva una constante que se refleje en un proceso de negociación y exigibilidad para con sus clientes.

Por su parte, los grupos focales fueron desarrollados en el marco de encuentros de ciudadanía, que eran espacios establecidos dentro del Proyecto VIH del Fondo Mundial, donde participaban diferentes instituciones de carácter gubernamental que representan las obligaciones del Estado colombiano desde la esfera territorial local y regional. Este escenario permitió vislumbrar la inconformidad poblacional, verbalizada por sus lideresas a través de expresiones tales como "la gente de nadie", arguyendo dicha expresión al sentimiento de abandono estatal, evidenciado principalmente en el deterioro constante que presenta la salud de la población femenina en el ejercicio de trabajo sexual.

\section{Determinantes sociales para la infección por VIH/ Sida en trabajadoras sexuales}

Los resultados de la investigación permitieron develar una serie de factores que ponen en evidencia la situación de desigualdad e inequidad en salud que viven las mujeres trabajadoras sexuales de la zona céntrica de la ciudad de Armenia. Estos factores se integran en diversas esferas correspondientes a aspectos sociales, políticos, económicos y ambientales, que serán retomados a continuación con el fin de realizar una discusión en torno a los determinantes sociales en salud y su relación con la prevalencia de la infección por VIH/Sida.

Como se evidenció en los resultados, el grupo poblacional de mujeres trabajadoras sexuales estudiadas carecen mayoritariamente de redes de apoyo, familiares o sociales, lo que permite comprobar que existe un elevado grado de estigma y discriminación que afecta la cohesión social hasta el punto de sumergir a estas mujeres en trayectos de marginación (Álvarez Castaño, 20o9). Esta situación se expresa en la ausencia de orientación en temas referidos a las ITS y VIH/Sida, la vulneración sistemática de los DDHH-DSR de estas mujeres, y la exclusión, marginación y estigmatización social a la que se ven sometidas, entre otras realidades. De otro lado, algunas de las mujeres hacen mención de la existencia de una barrera institucional de cara a los servicios de salud, que limita su acceso a estos servicios y, por ende, restringe las estrategias preventivas frente al VIH/Sida. En sus palabras:

Yo casi no voy al médico, es que allá lo miran a una muy mal, y no me gusta que me llamen por el nombre 
de la cedula, porque ellos como que no entienden que una es una mujer. (Mujer transgénero, 29 años)

Algunas veces me he sentido mal porque como saben que soy prostituta pues lo tratan diferente, deberían ser más humanos. (Mujer cisgénero, 33 años)

Un médico me dijo que yo tenía Sida, sabiendo que solo tengo VIH, y también me decía que yo era un riesgo para la sociedad y un vector, y a mí me parece que esa no es forma de decir las cosas. (Mujer transgénero, 30 años)

Estos testimonios evidencian además que persisten prejuicios por parte de algunos de los profesionales en salud, lo que genera acciones de discriminación institucional, de manera tal que estos procesos sociales se constituyen en nuevos DSS.

Por otra parte, en términos políticos, el status quo de las trabajadoras sexuales se limita a un escaso conocimiento sobre ITS, VIH/Sida y DDHH-DSR como ya se mencionó, pero además se constata la ausencia de escenarios de participación ciudadana para este grupo poblacional, y con ellos la falta de empoderamiento en materia de género. Según Barr et al. (2008), estas dinámicas se deben a la difusión que generan las responsabilidades en salud, derivado de la complejidad estructural de su sistema; es decir, las directrices nacionales plantean la exigencia de cumplimiento a entes territoriales, dificultando las acciones intersectoriales que requieren los DSS, coartando así la generación de políticas que emanen escenarios sólidos de participación, los cuales trabajen conjuntamente frente a la mitigación de la epidemia en poblaciones clave o, simplemente, operativicen los objetivos de universalización de la salud, teniendo en cuenta que el $23 \%$ de la población entrevistada se encuentra sin afiliación al SGSSS.

En cuanto a los aspectos económicos, se ponen de manifiesto las situaciones de pobreza extrema y pobreza que circundan el grupo objeto de estudio, no solo por las implicaciones que dicho factor tiene sobre la salud de las personas, sino por la exposición que genera frente a agentes transmisibles como el VIH/Sida. En este sentido, en el marco de los Objetivos de Desarrollo del Milenio 20002015 (ODM), del Programa de las Naciones Unidas para el Desarrollo (PNUD), se articularon las estrategias de reducción de la pobreza y de la mitigación del VIH/Sida, comprendiendo la relación dialéctica entre las dos problemáticas sociales bajo los ejemplos del Caribe y África. Estas afirmaciones comprometieron directamente al acceso gratuito a métodos preventivos, como condones y pruebas rápidas para VIH, como estrategia que promueve la no propagación de la epidemia, máxime cuando se trata de mujeres trabajadoras sexuales que desarrollan su actividad en espacios públicos, tales como calles y plazas, las cuales deben tener un monitorio permanente por parte de los funcionarios encargados de la salud pública direccionados por las secretarías técnicas de alcaldías y gobernaciones (PNUD, 2002). Sin embargo, dicho monitoreo no debe centrarse exclusivamente en los aspectos eminentemente biológicos y médicos de las mujeres, sino que deberían incorporar aspectos relativos a los contextos sociales, culturales y económicos, que en algunos casos afectan de manera directa el acceso de estas mujeres a los servicios de salud.

En este sentido, los aspectos ambientales del contexto de la vida cotidiana del grupo de mujeres estudiadas se caracterizan principalmente por un alto nivel de contaminación urbana, determinado por las emisiones de los vehículos automotores que circulan por el sector donde se ubican para desarrollar su labor. Además, se aprecia contaminación visual originada en la cantidad de vallas, afiches y material publicitario ubicado indiscriminadamente en toda la zona céntrica de la ciudad, así como altos índices de contaminación auditiva producida por los vehículos y por los establecimientos comerciales que no cumplen normas mínimas para controlar este tipo de contaminación.

Otros aspectos relevantes en materia ambiental que afectan a estas mujeres tienen que ver con las condiciones materiales y logísticas de los sitios destinados para la atención de sus clientes, tales como hoteles y residencias, donde las condiciones de iluminación, ventilación e infraestructura no ofrecen las condiciones físicas y estructurales idóneas para el ejercicio de su 
trabajo. De manera general, se evidencia que estos sitios no cumplen normas de limpieza y salubridad; además, sus estructuras se encuentran en mal estado, presentando humedades, materiales de construcción de baja calidad y, en algunos casos, carecen de baño o ducha para el aseo de los clientes y de las mujeres.

Estas condiciones también se extienden a las viviendas donde habitan las mujeres trabajadoras sexuales; algunas residen de manera permanente en estos hoteles o residencias, lo que aumenta su vulnerabilidad frente a todo tipo de enfermedades relacionadas con las condiciones ambientales.

Otros aspectos relativos al contexto en el cual habitan y laboran estas mujeres tienen que ver con los fenómenos sociales que se presentan a su alrededor, entre ellos el micro-tráfico de sustancia psicoactivas, el consumo de las mismas y el consumo generalizado de alcohol. Dicha lectura del entorno inmediato evidencia que el $45 \%$ de las mujeres entrevistadas consumen algún tipo de SPA, además del consumo permanente de bebidas alcohólicas como parte integral de la negociación que llevan a cabo estas mujeres y sus clientes.

Por tanto, es fundamental tener en cuenta que el factor socioambiental de los DSS con relación al VIH/Sida predispone el encuentro sexual bajo los efectos de sustancias psicoactivas, tanto legales como ilegales, subyugando la posibilidad del uso de métodos preventivos, convirtiéndolo en un comportamiento de riesgo presuntivo para la infección (Chincha et al., 2008).

Por consiguiente, la vulnerabilidad de las mujeres trabajadoras sexuales del centro de la ciudad de Armenia con relación al VIH/Sida y otras ITS es multicausal, es decir, existen diversos factores que aumentan su vulnerabilidad y, por tanto, el riesgo de que estas mujeres puedan infectarse de VIH/Sida. Estas causas pueden ser de origen social, ambiental, económico, político y personal. Todos estos resultados vienen a corroborar lo que afirman autores como Liscano Pinzón y Estrada Montoya (2015), según los cuales los determinantes estructurales referidos al género y a la condición socioeconómica ejercen un mayor condicionamiento sobre el comportamiento del VIH/Sida, siendo necesario considerar estos aspectos en la gestión de la pandemia.

\section{Conclusiones}

Los Determinantes Sociales de la Salud para el caso de las mujeres trabajadoras sexuales en el municipio de Armenia son de muy diversa índole, podemos iniciar mencionando aquellos relacionados con el contexto socioeconómico y político, donde se hace evidente la falta de políticas públicas en materia de salud y protección social, educación y empleo, que involucren de manera directa a esta población y que, además, desde un enfoque diferencial, diseñen y propongan acciones que permitan disminuir su vulnerabilidad frente al VIH/Sida y otras ITS.

Otro de los DSS que influye de manera directa sobre las mujeres trabajadoras sexuales es la cultura de la región donde se ubican y la valoración social de su trabajo; en el primer caso debido al machismo imperante en esta zona que determina que estas mujeres se encuentren expuestas a la violencia física, psicológica y económica. Dichas situaciones limitan, por ejemplo, la utilización de métodos anticonceptivos y una dificultad manifiesta en la negociación para el uso del condón con sus clientes. En segundo lugar, la valoración social de la prostitución genera una serie de prejuicios y estereotipos, según los cuales se considera que las trabajadoras sexuales pueden acceder a cualquier tipo de actividad sexual a cambio de dinero, y además que no es indispensable el uso del condón en sus prácticas sexuales. Estas situaciones conducen a aumentar la vulnerabilidad de estas mujeres y aumentar el riesgo frente al VIH/Sida y otras ITS.

Vale la pena anotar que los aspectos referidos al estigma, al prejuicio y a la discriminación son mayores para el caso de las mujeres transgénero, que se ven afectadas más frecuentemente por situaciones de violencia y discriminación que las mujeres cisgénero; además, debido a las situaciones de marginación y exclusión social, las mujeres transgénero tienen una mayor incidencia frente al VIH/Sida.

La situación antes descrita nos lleva a identificar otro tipo de DSS referidos a la posición socioeconómica, en este caso los referidos a la identidad sexual que ponen en desventaja y mayor 
riesgo a las mujeres transgénero que a otros grupos sociales. En este sentido, existe un sentimiento de menosprecio social frente a estas mujeres por su condición identitaria, conduciéndolas a situaciones de marginación social. Otro de los aspectos referidos a la posición socioeconómica está relacionado con la educación, como se puede comprobar en las entrevistas. Si bien no existe un limitante para el acceso de estas mujeres a la educación formal, sí se hacen presentes factores que limitan su permanencia en los procesos educativos, como el bullying al cual se ven sometidas especialmente las mujeres transgénero, o las necesidades de colaborar con el ingreso económico para sus familias que las obliga a abandonar el ciclo educativo.

De otro lado, se identificaron determinantes sociales en salud referidos al capital social y a la cohesión social, es decir, a las redes sociales con las cuales cuentan estas mujeres para hacer frente a las situaciones cotidianas de su vida. En la mayor parte de los casos, las mujeres entrevistadas no cuentan con apoyos emocionales ni materiales provenientes de sus familias o amigos, lo que aumenta su vulnerabilidad social. Además, se observaron algunos DSS relacionados con los aspectos ambientales, referidos al contexto físico donde las mujeres desarrollan su actividad laboral y donde residen habitualmente.

Existen DSS relacionados con factores psicológicos, tales como el consumo de sustancias psicoactivas y bebidas alcohólicas, parte permanente de la actividad de estas mujeres. Como se puede apreciar, las condiciones sociales condicionan en buena medida la vulnerabilidad de estas mujeres frente al VIH/Sida y a las ITS, y no se debe considerar que esta vulnerabilidad tenga una única causa, por el contrario, es multicausal y debe ser intervenida y analizada desde esta perspectiva.

En este sentido, se puede decir que existe una relación directa entre los determinantes sociales en salud con la prevalencia de la infección por VIH/Sida en mujeres trabajadoras sexuales de la zona céntrica de la ciudad de Armenia. Además que los factores sociales que en el marco de la inequidad convergen con el prejuicio, el estigma, la discriminación, la inexistencia de redes de apoyo sociofamiliares, y estos, a su vez, con la falta de orientación, la vulneración de derechos, la exclusión y la segregación, generando un contexto social altamente vulnerable para las mujeres trabajadoras sexuales.

Finalmente, y en términos políticos, la ausencia de programas de promoción y prevención que vinculen las necesidades de las mujeres trabajadoras sexuales del contexto analizado se prospectan en la agenda pública superfluas. Es así como proyectos en DDHH-SSR y promoción y prevención con enfoque en VIH/Sida resultan discontinuos y, por ende, con poco impacto social, revelando la existencia de estrategias educativas formales e informales erróneas, y con ellas, el incumplimiento del Estado frente a la universalización de los servicios de salud. Sumado a esto, la ausencia de liderazgo de las trabajadoras sexuales limitan las acciones de incidencia política, que además no permiten el fortalecimiento comunitario y el empoderamiento de este colectivo. Por ende, la acción intersectorial asocia el conjunto de componentes que mitigan los DSS, por ello se hace necesario, como lo indica Barr et al. (2008, p. 7), ahondar en:

la complejidad de los factores sociales, políticos, económicos y ambientales que inciden sobre la salud y las desigualdades en materia de salud, aunada al hecho de que la mayoría de esos determinantes está fuera de la jurisdicción exclusiva del sector de salud, obliga a este último a actuar en colaboración con otros sectores gubernamentales y sociales para responder con eficacia a esos factores que repercuten sobre la salud y el bienestar de la población.

Es decir, la complejidad estructural del sistema de sanidad en Colombia, a pesar de estar compuesto por entes territoriales independientes económicamente hablando, debe propender por el desarrollo de acciones articuladas con otras dependencias administrativas estatales que reconozcan y comprendan de forma integral la realidad social de las poblaciones clave frente al VIH/Sida. Por tanto, dicha articulación debe se evidenciar no solo en el descenso de la infección, sino también en la participación activa y en el empdoeramiento de las personas para el desarrollo de programas desde una perspectiva de planificación comunitaria necesaria para resolver las inequidades sociales y de salud, más allá de la ambivalencia que 
se esconde tras el trabajo sexual como un asunto subjetivo, y la objetividad estatal que requiere el VIH/ Sida como una cuestión de salud pública.

\section{Referencias}

ÁLVAREZ CASTAÑO, L. S. Los determinantes sociales de la salud: más allá de los factores de riesgo. Revista Gerencia Política en Salud, Bogotá, v. 8, n. 17, p. 69-79, 2009. Disponível em: <https://goo.gl/Q3AccK>. Acesso em: 13 fev. 2015. ASOCIACIÓN ÁGORA COLOMBIA. Diagnóstico comunitario de mujeres y mujeres trans trabajadoras sexuales de la zona céntrica de la ciudad de Armenia. Armenia, 2013.

ASOCIACIÓN ÁGORA COLOMBIA. Prevalencia de la infección por VIH en mujeres trabajadoras sexuales de la zona céntrica de la ciudad de Armenia. Armenia, 2015.

BARR, V. et al. Equidad en salud a través de la acción intersectorial: un análisis de estudio de casos en 18 países. Ginebra: OMS, 2008. Disponível em: <https://goo.gl/uitjgE>. Acesso em: 10 mar. 2015.

BORDIGNON, N. A. El desarrollo psicosocial de Erik Erikson: el diagrama epigenético del adulto. Revista Lasallista de Investigación, Caldas, v. 2, n. 2, p. 5o-63, 2005 .

CHINCHA, O. L. et al. Asociación entre el consumo de alcohol y la infección por virus de inmunodeficiencia humana. Revista Chilena de Infectología, Santiago de Chile, v. 25, n. 1, p. 49-53, 2008.

COLOMBIA. Ministerio de Salud y Protección Social. Informe GARPR 2014. Seguimiento de la declaración de compromiso sobre el VIH/sida. 2014. Disponível em: <https://bit.ly/2NgadaH>. Acesso em: 23 ago. 2018.

DÍAZ-BRAVO, L. et al. La entrevista, recurso flexible y dinámico. Revista de Investigación en Educación Médica, Ciudad de México, v. 2, n. 7, p. 162-167, 2013.
JUAN-MARTÍNEZ, B.; CASTILLO-ARCOS, L. C. Determinantes sociales de salud asociados al virus de la inmunodeficiencia humana en mujeres indígenas del norte de Oaxaca, México. Revista Enfermería Clínica, Amsterdam, v. 26, n. 1, p. 81-84, 2016.

LISCANO PINZÓN, Y. D. L.; ESTRADA MONTOYA, J. H. E. Exploración y análisis a los determinantes sociales estructurales e intermedios de la pandemia del VIH-Sida. Acta Odontológica Colombiana, Bogotá, DC, v. 5, n. 1, p. 117-131, 2015. Disponível em: <https://goo.gl/vgu7nK>. Acesso em: 13 fev. 2015 .

MARTÍNEZ-SALGADO, C. El muestreo en investigación cualitativa: principios básicos y algunas controversias. Ciência e Saúde Coletiva, Rio de Janeiro, v. 17, n. 3, p. 613-619, 2012.

OMS - ORGANIZACIÓN MUNDIAL DE LA SALUD. Subsanar las desigualdades en una generación: alcanzar la equidad sanitaria actuando sobre los determinantes sociales de la salud. Ginebra, 2008. Disponível em: <https://goo.gl/rWdgxy>. Acesso em: 20 fev. 2017.

OMS - ORGANIZACIÓN MUNDIAL DE LA SALUD. Reducir las inequidades sanitarias actuando sobre los determinantes sociales de la salud. Ginebra, 2009. Disponível em: <https://bit.ly/2MRFOkA>. Acceso em: 20 fev. 2017.

ONU - ORGANIZACIÓN DE LAS NACIONES

UNIDAS. El progreso de América Latina y el Caribe hacia los Objetivos de Desarrollo del Milenio: desafíos para lograrlos con igualdad. Washington, DC: Cepal, 2010.

ONUSIDA. Estadísticas mundiales sobre el VIH de 2017. Hoja Informativa, [S.l.], jul. 2018. Disponível em: <https://goo.gl/wQnGn2>. Acesso em: 15 dez. 2017.

PNUD - PROGRAMA DE LAS NACIONES UNIDAS PARA EL DESARROLLO. VIH/Sida y estrategias para la reducción de la pobreza. New York, 2002. PROSALUS. Salud y Desarrollo. VIH/Sida y determinantes sociales de la salud. Madrid, 2012. 
Disponível em: <https://goo.gl/tFsLrM>. Acesso em: 3 jul. 2016.

QUECEDO, R.; CASTAÑO, C. Introducción a la metodología de la investigación cualitativa. Revista de Psicodidáctica, Lejona, n. 14, p. 5-39, 2002.

RESTREPO PINEDA, J. E. Análisis comparativo de las percepciones sobre el VIH/Sida de varones homosexuales y bisexuales colombianos, con experiencia migratoria o sin la misma. Revista de Salud Pública, Bogotá, DC, v. 18, n. 1, p. 13-25, 2016.

SANTOS PADRÓN, H. S. Los determinantes sociales, las desigualdades en salud y las políticas, como temas de investigación. Revista Cubana
Salud Pública, Boyeros, v. 37, n. 2, p. 136-144, 2011. Disponível em: <https://goo.gl/eXVZp9>. Acesso em: 13 fev. 2017.

TOVAR-CUEVAS, L. M.; ARRIVILLAGA-

QUINTERO, M. VIH/Sida y determinantes sociales estructurales en municipios del Valle del Cauca-Colombia. Revista Gerencia y Políticas de Salud, Bogotá, DC, v. 10, n. 21, p. 112-123, 2011. Disponível em: <https://goo.gl/3mJyMx>. Acesso em: 20 maio 2017.

VEGA, J.; JADUE, L.; MARÍN, F. Determinantes sociales de la salud en Chile: en la perspectiva de la equidad. Santiago de Chile: ICES, 2005.

\section{Contribución de los autores}

Aguirre y Vela fueron responsables de la concepción del estudio, así como del levantamiento de la información. Restrepo contribuyó a la sistematización y análisis de los datos. Los tres autores participaron en la redacción del artículo.

Recibido: $26 / 01 / 2018$

Re-presentado: 26/04/2018

Aprobado: 02/07/2018 